\title{
Studies on Mechanical Behaviour of Aluminium-Silicon Carbide-Copper Metal Matrix Composite
}

\author{
Shreyas $P S^{1}$, Shriramkumar $S^{2}$, Sruthisagar $\mathrm{R}^{3}$, Vijaya Ramnath $\mathrm{B}^{4}$ and Elanchezhian $\mathrm{C}^{5}$ \\ ${ }^{1,2,3}$ Department of Mechanical Engineering, Sri Sairam engineering College, Chennai \\ ${ }_{4}^{4}$, Professor, Dept. of Mechanical Engineering, Sri Sairam Engineering. College, Tamil Nadu, India \\ 5. Professor, Dept. of Mechanical Engineering, Sri Sairam Engineering. College, Tamil Nadu,India \\ E-mail':tryshreyas@gmail.com E-mail': vijayaramnathb@gmail.com
}

\begin{abstract}
Metal matrix composites (MMC) are the combination of two or more dissimilar base metals which in turn gives new metal. Composites have better properties than their base material. Nowadays, composites play the major role in manufacturing industries especially in automotive industry. This paper reveals the reinforcement of Aluminium alloy (6061) with Silicon Carbide and Copper in different ratios to produce new composite using stir casting technique in normal atmospheric temperature. In this work, mechanical behavior of the composite namely tensile strength, hardness and Flexural strength were evaluated. It was observed that sample 2 shows highest tensile strength of $155 \mathrm{MPa}$ with hardness 73 . The result shows that the hybrid composite had better mechanical property.
\end{abstract}

\section{Introduction}

Nowadays composite materials are replacing conventional materials due to their high strength to weight ratio, bio degradable nature, wear and corrosion resistance. Mohan Kumar et al [1] found the Ultimate tensile strength of Al-4.5 wt $\% \mathrm{Cu}-2 \mathrm{wt} \%$ Fly ash $-3 \mathrm{wt} \%$. $\mathrm{SiC}$ composites to be higher than the Base Matrix composite of $\mathrm{Al}-4.5 \mathrm{wt} \%$ of Copper alloy. They stated that this material exhibits high strength to weight ratio and good fatigue resistance. Anilkumar et al [2] stated that the bonding between the matrix material and Fly ash is good and he also observed that there is no gap between the Particle and matrix Material. Itskos et al [3] discovered that by adding the Fly Ash to the MMC, it enhances the tribo-performances of the composites. Shivaprakash et al [4] found that the heat treated Fly ash composite has comparatively better characteristics to non heat treated composites, especially the wear performance is better for water quenched specimen than air cooled specimen and non-heat treated specimens. Arun Kumar et al [5] stated that the alumina coated stirrer blades will prevent the migration of ferrous ions from stirrer to the molten metal. They also found that the e-glass and Fly ash composites with aluminium (Al 6061) increase the tensile strength by $60-70 \%$. Vivekananthan et al [6] stated that by adding the Fly ash and $\mathrm{Mg}$ in aluminum results in increased hardness from $58 \mathrm{BHN}$ to $86 \mathrm{BHN}$. Mahendra et al [7] found that the fluidity and density of the composites decreases while tensile strength, impact strength, compression strength and dry sliding wear resistantance increase due to increase in percentage of
Flyash. Surendra Kumar Patel et al [8] discovered that both the reinforcements $50 \% \mathrm{SiC}$ and $50 \%$ of Zircon sand on aluminium ADC-12 alloy give better compressive strength compared to others. Ramanpreet Singh and Rahul Singla [9] stated that by increasing the weight fraction of Silicon Carbide, the wear rate gets reduced linearly. Ashok Atulker et al [10] found that the wear rate remains constant more or less in the pressure range of $0.5 \mathrm{~N} / \mathrm{mm}^{2}$ to $0.6 \mathrm{~N} / \mathrm{mm}^{2}$, but the wear rate increases steadily up to the normal pressure of $0.5 \mathrm{~N} / \mathrm{mm}^{2}$, and increases rapidly that due to adhesive wear. Vinod Kumar et al [11] stated that the wear rate of the composition (Al6061T6/15\% $\mathrm{SiC} / 15 \% \quad \mathrm{Al} 2 \mathrm{O} 3 \mathrm{MMC}$ ) is highly influenced by the applied load. Gaurav Mahajan et al [12] concluded that by adding $\mathrm{SiC}$ and $\mathrm{TiB} 2$ to the matrix material, the wear rate and coefficient of friction gets decreased. They also found that by adding SiC and TiB2 to the aluminium alloy (A16061), Hardness is increased considerably. By using this Composition (AL/10\%SiC) the hardness value increased by $38 \%$, also by using the composition $(\mathrm{Al} / 10 \% \mathrm{SiC} / 5 \% \mathrm{TiB} 2)$ the hardness value increases by 35.7 . \%. Francis Xavier et al [13] stated that, by increasing the Wet grinder Stone Dust particle (WSD) content from $10 \%$ wt to $20 \%$ wt in a composite, the hardness and wear resistance increases but the ductility reduces. Aluminium with silicon carbide as reinforcement has been done by various authors [14, 15]. Meena et al [16] stated that by increasing the reinforcement $(\mathrm{SiC})$ size (220 mesh, 300 mesh and 400 mesh) the impact strength decreases. Omkar Pansare et al stated that the wettability property increases by increasing the $\mathrm{Mg} \%$ in the melt. They also stated that by 
preheating the mould, we can avoid porosity in casting and increase the fluidity and proper fluid distribution. Vijaya Ramnath et al $[18,19,20]$ studied the compression and chemical Properties of Aluminium Nano Composite and also reviewed aluminium metal matrix composites. Radhika et al [21] stated that the incorporation of Graphite as primary reinforcement, which forms the protective layer between the pin and the counter face, increases wear resistance. Manoj Singla et al [22] found that a sample which contains $25 \% \mathrm{SiC}$ gives the best value in Hardness and Toughness, i.e., Hardness 45.5 BHN and Impact Strength $36 \mathrm{~N}-\mathrm{m}$. Beyond this weight fraction, the hardness decreases because $\mathrm{SiC}$ particles interact with each other resulting in cluster formation Since, no work has been carried out using Silicon Carbide-Copper as reinforcement for Aluminium, this paper aims to fabricate metal matrix composites using combination.

\section{Materials used}

Aluminium Alloy (6061): This alloy is manufactured based on the ASTM E 1251- 07 optical emission spectrometry. Density of this material is $2.65 \mathrm{~g} / \mathrm{cm}^{3}$. This alloy has excellent corrosion resistance in both ordinary and marine conditions. By Anodic Treatment this property can be further enhanced. Al 6061 rods are used in this process that are melted before the reinforcement added to the molten metal.

Silicon Carbide: Silicon Carbide is the natural resource which melts at around $2,730{ }^{\circ} \mathrm{C}$ and having hardness of 9.0-9.5 Mohs. Silicon Carbide powder is used in this Composite as a reinforcement.

Copper: Copper powder is used as reinforcement in this Composite. Copper usually melts at a temperature of $1500{ }^{\circ} \mathrm{C}$. Copper is known to possess good ductility, thermal conductivity and electrical conductivity.

\section{Fabrication of composite}

Required amount of raw Aluminum ingots (6061) will be taken in graphite crucible and it will be placed for 2 hours inside the furnace in $850-900^{\circ} \mathrm{c}$. At the same time the Silicon Carbide and Copper powder will get preheated in the same temperature. When the aluminum ingots melts completely, the Degasser added to the molten metal which removes all the gasses and impurities presents in the molten metal. Then the cover-all powder is added, which forms a layer on top of the molten metal and it retains heat inside the crucible. Then the preheated
Silicon Carbide and Copper will be added in the molten metal. Now, the stirring process will be carried out for 10 minutes and the stirring temperature is maintained in 650$700^{0} \mathrm{C}$. To avoid casting defects the die will be preheated to $500^{\circ} \mathrm{C}$, when it reaches $500^{\circ} \mathrm{C}$ the molten metal poured in to the die $(100 \times 100 \times 10 \mathrm{~mm})$ and which is allowed to solidify. Table 1 shows composition of MMC fabricated in this work.

Table 1. Material Composition

\begin{tabular}{|l|l|l|l|}
\hline $\begin{array}{l}\text { Name of } \\
\text { Sample }\end{array}$ & $\begin{array}{l}\text { Percentage } \\
\text { of Al 6061 }\end{array}$ & $\begin{array}{l}\text { Percentage } \\
\text { of SiC }\end{array}$ & $\begin{array}{l}\text { Percentage } \\
\text { of Cu }\end{array}$ \\
\hline Sample 1 & 94.25 & 0.75 & 5 \\
\hline Sample 2 & 93.5 & 1.5 & 5 \\
\hline Sample 3 & 92.5 & 2.5 & 5 \\
\hline
\end{tabular}

\section{Testing of composite}

4.1 Tensile test: Tensile test of the fabricated hybrid composite sample was prepared as per ASTM: D638. This test was carried out in Universal Testing Machine, Which has done in the normal atmospheric temperature $\left(35^{\circ} \mathrm{C}\right)$ and controlled relative humidity.

4.2 Hardness test: Hardness is resistance to indentation and by which the hardness was determined by permanent depth of indentation. The hardness test of a material was done on Brinell Hardness Testing Machine, Avery make $3000 \mathrm{kgf}$ and it was followed by ASTM E10 standard. This test was performed by $10 \mathrm{~mm}$ ball by applying $3000 \mathrm{kgf}$ load.

Brinell Hardness $(\mathrm{HB})=$

$$
\frac{2 F}{\pi D(D-\sqrt{D-d})}
$$

Where,

$$
\begin{aligned}
& \mathrm{D}=\text { Ball diameter } \\
& \mathrm{d}=\text { Impression } \\
& \text { diameter } \mathrm{F}=\text { Load }(\mathrm{N}) \\
& \mathrm{HB}=\text { Brinell hardness number }
\end{aligned}
$$


4.3 Flexural Test: The Flexural (Compression) test was done on Universal Testing Machine UTN 40 Model. Here, the test specimen was prepared as per the ASTM E8 Standard.

\section{Results and discussions}

\subsection{Tensile Properties}

The result of tensile test is shown in graph and Fig. 1, from which it is concluded that the sample-2 $(1.5 \% \mathrm{Sic})$ has high strength than the other two compositions. This is due to the presence of Silicon Carbide, but not in enough of a quantity to skew the strength too much towards either side.

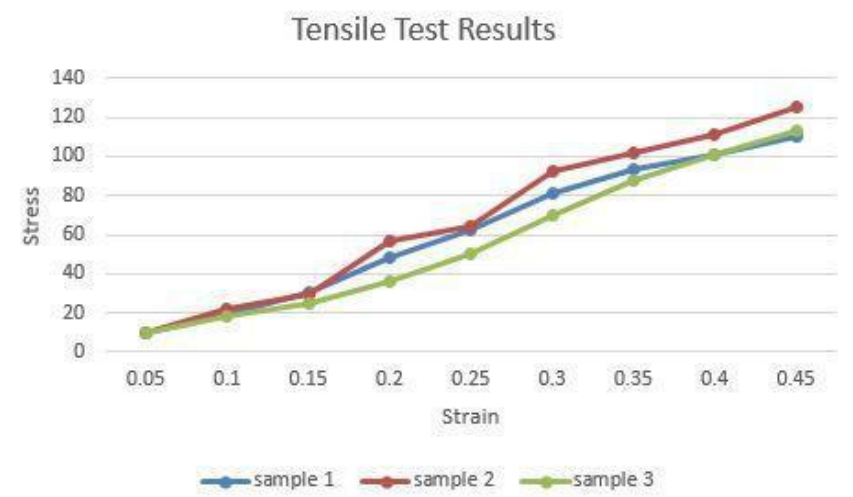

1(A) Results of Tensile Test- Graph

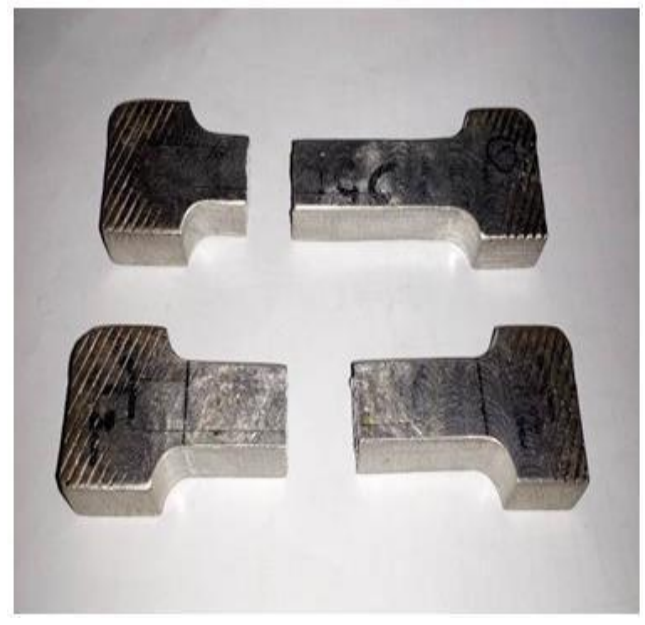

1(B) Result of Tensile Test- Specimen

\subsection{Hardness Properties}

Fig. 2 (A \& B) show the result of hardness test, from which it is concluded that sample 2 which has $1.5 \%$ of
Silicon Carbide and 5\% of copper has more hardness than the other 2 samples. This is because Silicon carbide in higher quantities can make the composite brittle and here it is being balanced by the copper present.

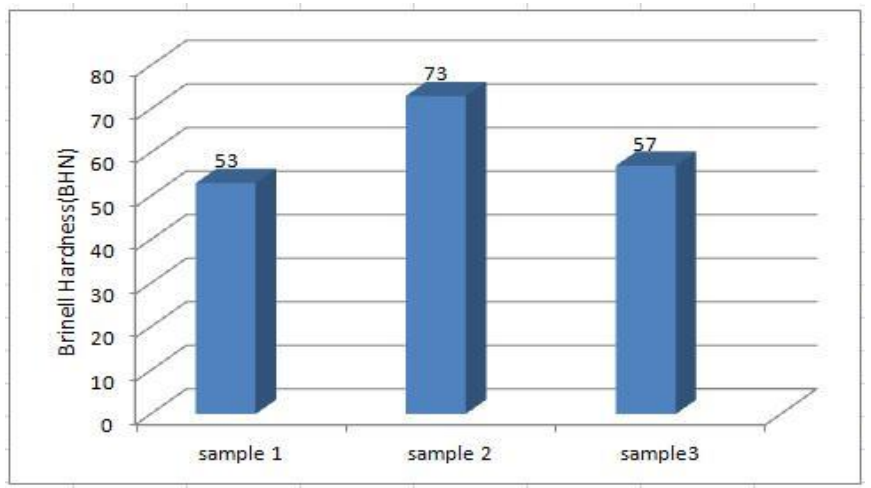

2(A) Result of Hardness Test- Graph

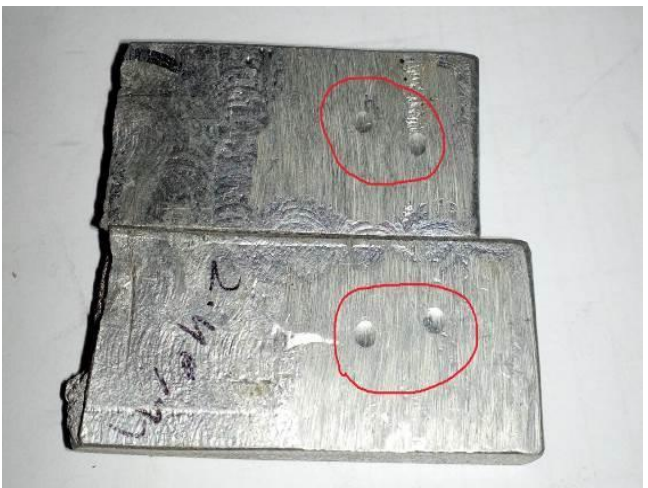

2(B) Result of Brinell Hardness Test- Specimen

\subsection{Flexural Properties}

Fig. 3 shows the result of Flexural Test, from which it is concluded that the sample which contains $1.5 \%$ of Silicon Carbide and $5 \%$ of copper is greater than the other samples. This is due to the presence of Silicon Carbide and Copper, which resist the bending property of a composite as compared to the other samples.

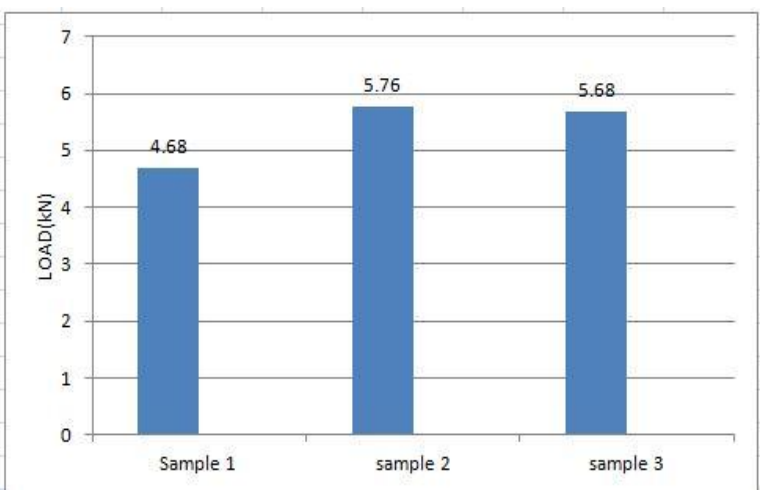

3(A) Result of Flexural Test-Graph 


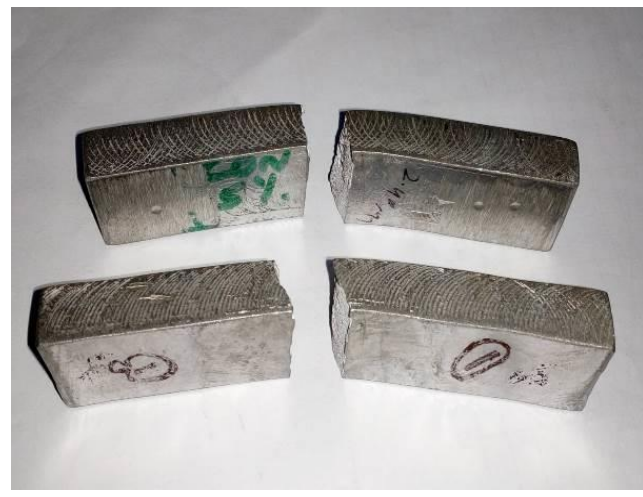

3(B) Result of Flexural Test- Specimen

\section{Conclusion}

In this work the tensile, flexural and hardness of $\mathrm{Al}$ metal matrix composites reinforced with Silicon Carbide and Copper were investigated.

It was found those samples which contain $1.5 \%$ of $\mathrm{SiC}$ and 5\% Copper has more tensile strength and hardness than the rest of the samples. This may be attributed to the presence of less percentage of Silicon carbide which is balanced by the presence of Copper.

In Flexural (bending) test the sample (Sample 2) which contains $1.5 \% \mathrm{Sic}$ and $5 \% \mathrm{Cu}$ has more flexural ability compared to other samples. This may be due to the presence of copper which resists bending and balances the brittleness invoked by the presence of Silicon Carbide.

\section{References}

1. T.S Mohan kumar, S. Srinivas, M Ramachandra, K.V Mahendra and Madeva Nagaral. Effect of Fly ash and sic Particulates Addition on Mechanical Properties of $\mathrm{Al}-5 \mathrm{wt} \% \mathrm{Cu}$ Alloy Composites. IOSR-JMCE. Vol12, issue4, PP 01-05, (2015)

2. H.C. Anilkumar, H.S. Hebbar and K.S. Ravishankar Mechanical Properties Of Fly Ash Reinforced Aluminium Alloy (Al6061) Composites. IJMME. Vol.6, No.1, PP 41-45. (2011)

3. Itskos G, Moutatsou A, Rohatgi P, Koukouzas N, Vasilatos C, Katsika E. Compaction of High-Ca Fly Ash-Al- and Al-Alloy-Composites: Evaluation of their Microstructure and Tribological Performance. Coal Combustion and Gasification Products. Vol.3, PP 75-82 (2011)

4. Shivaprakash.Y.M, Yadavalli Basavaraj, K.V.Sreenivasa Prasad Comparative study of tribological characteristics of Al2024+10\% fly ash composite in non-heat treated and Heat treated conditions. International Journal of Research in Engineering and Technology. , Vol2, Issue11. (2013)

5. Arun Kumar M. B. and R. P. Swamy Evaluation of Mechanical Properties of Al6061, Flyash and EGlass Fiber Reinforced Hybrid Metal Matrix Composites. ARPN Journal of Engineering and Applied Sciences. , VOL6, NO.5. (2011)

6. Vivekananthan M and Senthamarai K Experimental Evaluation of Aluminium-Fly Ash Composite Material to Increase the Mechanical \&Wear
Behaviour by Stir Casting Method. CARE Journal of Applied Research. (ISSN 2321-4090) (2013)

7. K.V. Mahendra and K. Radhakrishna Fabrication of $\mathrm{Al}-4.5 \% \mathrm{Cu}$ alloy with fly ash metal matrix composites and its characterization. Materials Science-Poland. , vol. 25, pp. 57-68.

8. Surendra Kumar Patel, Raman Nateriya, G. Dixit Microstructural Analysis, Microhardness and Compressive Behaviour of Dual Reinforced Particles Adc-12 Alloy Composite. International Journal of Engineering Technologies and Management Research., Vol.1, Issue1, PP 23-34 (2015)

9. Ramanpreet singh and Rahul Singla Tribological Characterization of Aluminium-Silicon Carbide Composite Prepared by Mechanical Alloying. International Journal of Applied Engineering Research. Vol.7, No.11. (2012)

10. Ashok Atulker, Kartikeya Tripathi and Vinod Pare Wear analysis of Aluminium Alloy for automobile piston against cast iron for cylinder liner. $12^{\text {th }}$ National Conference on Machines and Mechanisms (NaCoMM-2005) PP 281-283

11. Vinod Kumar, Phool kumar and Surender Sharma Wear Characterization of Aluminium/Sic/A12O3 Hybrid Metal Matrix Composite Using Taguchi Technique. International Journal of Innovative Research \& Development Vol. 3 Issue 1,PP 34-40 (2014)

12. Gaurav Mahajan, Nikhil Karve, Uday Patil, P. Kuppan and K. Venkatesan Analysis of Microstructure, Hardness and Wear of Al-SiC-TiB 2 Hybrid Metal Matrix Composite. Indian Journal of Science and Technology. Vol 8(S2), PP 101-105. (2015)

13. L.Francis Xavier and Paramasivam Suresh Wear Behavior of Aluminium Metal Matrix Composite Prepared from Industrial Waste. The Scientific World Journal, Vol. 2016, Article ID 6538345, 8 pages, (2016)

14. Siddique Ahmed Ghias B.Vijaya Ramnath, Investigation of Tensile Property of Aluminium SiC Metal Matrix, International Journal of Applied Mechanics and Materials. Volume 766767, PP 252-256. (2015)

15. P.Subramaniya Reddy, R.Kesavan, and B.Vijaya Ramnath, "Investigation of Mechanical Properties of Aluminium6061-Silicon Carbide, Boron Carbide Metal Matrix Composite “, Silicon, Volume 1, PP 18, (2016)

16. K. L. Meena, Dr. A. Manna, Dr. S. S. Banwait, Dr. Jaswanti an Analysis of Mechanical Properties of the Developed Al/SiC-MMC's. American Journal of Mechanical Engineering, Vol. 1, No. 1, PP 14-19. (2013)

17. Omkar Pansare, S.G.Kulkarni, S.S.Kulkarni. Statistical analysis by Taguchi method for buckling of aluminium matrix composite plate manufactured using Stir Casting, International Journal of Science, Engineering and Technology Research, Vol. 4, Issue.7. (2015)

18. B. Vijaya Ramnath, C.Parswajinan,C. Elanchezhian, S.V. Pragadeesh,C.Kavin,P.,R. Ramkishore, V. Sabarish, Experimental Investigation of Compression and Chemical Properties of 
Aluminium Nano Composite, International Journal Applied Mechanics and Materials, Volume 680, PP 7-10. (2014)

19. B.Vijaya Ramnath, C. Elanchezhian, RM. Annamalai, S.Aravind, T. Sri Ananda Atreya, V. Vignesh, C.Subramanian, Aluminium metal matrix composites - a review, Reviews on advanced material science, Volume 38, PP 55-60. (2014)

20. B.Vijaya Ramnath, C. Elanchezhian, M.Jaivignesh, S. Rajesh, C. Parswajinan, A. Siddique Ahmed Ghias, Evaluation of Mechanical Properties of Aluminium Alloy-Alumina-Boron Carbide Metal Matrix Composites. Materials and design, Volume 58, PP 332-338. (2014)

21. N.Radhika, R. Subramanian, S. Venkat Prasat Tribological Behaviour of Aluminium/Alumina/Graphite Hybrid Metal Matrix Composite Using Taguchi's Techniques. Journal of Minerals \& Materials Characterization \& Engineering, Vol. 10, No.5, PP.427-433, (2011)

22. Manoj Singla, D. Deepak Dwivedi, Lakhvir Singh and Vikas Chawla Development of Aluminium Based Silicon Carbide Particulate Metal Matrix Composite. Journal of Minerals \& Materials Characterization \& Engineering, Vol. 8, No.6, PP 455-467, (2009). 